\title{
Intrahepatic stones: The percutaneous approach
}

\author{
Horst Neuhaus MD
}

\begin{abstract}
H Neuhaus. Intrahepatic stones: The percutaneous approach. Can J Gastroenterol 1999;13(6):467-472. Intrahepatic stones are prevalent in the Far East, whereas they are infrequently seen in Western countries. Hepatolithiasis can cause recurrent attacks of cholangitis, with a risk of liver abscesses, sepsis or hepatic failure. Immediate biliary decompression can usually be achieved by endoscopic or percutaneous transhepatic drainage. Definitive treatment should aim for complete elimination of bile stasis and removal of all stones. Hepatic resection promises the best long term results when the disease is limited to segments or the left liver lobe. Endoscopic retrograde choledochopancreatography is not well established for intrahepatic stones because of frequent failures due to associated biliary strictures, angulated ducts or peripherally impacted concrements. In contrast, percutaneous procedures can be easily performed through a $\mathrm{T}$ tube tract for residual stones after surgery. Establishment of a transhepatic fistula allows a targeted approach to liver segments with catheters or miniscopes, without the need for laparotomy. Biliary strictures can be dilated with balloons, and intrahepatic stones can be removed with baskets under fluoroscopic or cholangioscopic control. These techniques can be combined with electrohydraulic lithotripsy or laser lithotripsy for disintegration of impacted calculi. The risk of stone recurrence is particularly high in patients with associated biliary stenoses. Temporary or long term transhepatic intubation is a promising approach in these cases. The optimal management of intrahepatic stones remains a challenging task that requires an experienced team of gastroenterologists, surgeons and radiologists.
\end{abstract}

Key Words: Endoscopy; Intrahepatic stones; Percutaneous transhepatic cholangiography

\section{Calculs intra-hépatiques : Approche percutanée}

RÉSUMÉ : Les calculs intra-hépatiques sont prévalents en Extrême-Orient, alors qu'ils sont rares dans les pays occidentaux. L'hépatolithiase peut provoquer des crises récurrentes de cholangite qui s'accompagnent d'un risque d'abcès hépatique, de septicémie ou d'insuffisance hépatique. La décompression biliaire immédiate peut habituellement être obtenue par endoscopie ou par drainage trans-hépatique percutané. Le traitement définitif devrait viser une élimination complète de la stase biliaire et l'exérèse de tous les calculs. La résection hépatique donne les résultats les meilleurs à long terme, lorsque la maladie se limite à des segments ou à la portion gauche du foie. L'utilité de la cholédoco-pancréatographie endoscopique rétrograde n'est pas bien établie dans le cas des calculs intra-hépatiques en raison des échecs fréquents attribuables à des strictures biliaires, à l'angulation des canaux ou à la présence des calculs en périphérie. Par contre, les interventions percutanées peuvent être facilement effectuées au moyen d'un tube en $\mathrm{T}$ pour les calculs résiduels après la chirurgie. La création d'une fistule trans-hépatique permet une approche ciblée aux segments du foie au moyen de cathéters ou de miniscopes, sans recours à la laparotomie. Les strictures biliaires peuvent être dilatées au moyen de ballonnets et les calculs intra-hépatiques peuvent être retirés sous fluoroscopie ou cholangioscopie. Ces techniques peuvent être combinées à la lithotripsie électrohydraulique ou à la lithotripsie au laser pour désintrégration des calculs. Le risque de récidive est particulièrement élevé chez les patients qui présentent des sténoses biliaires. Une intubation trans-hépatique temporaire ou permanente est une approche utile dans de tels cas. Le traitement optimum des calculs intra-hépatiques reste une tâche complexe qui exige le travail en collaboration d'une équipe expérimentée de gastro-entérologues, de chirurgiens et de radiologues.
$\mathrm{I}_{\mathrm{n}}^{\mathrm{n}}$ ntrahepatic stones are endemic in East Asia, with the highest incidence found in Taiwan, Hong Kong and southern China. Environmental conditions, dietary habits and parasitic infections may have an impact on this phenomenon. In Western countries, this disease is rare and mainly associated with bile stasis caused by postoperative, inflammatory or neoplastic bile duct strictures, common bile duct stones or cystic abnormalities (1). Enteric bacteria producing beta-glucuronidase may cause infection of the static bile with deconjugation of bilirubin diglucuronide. Hydroly- 


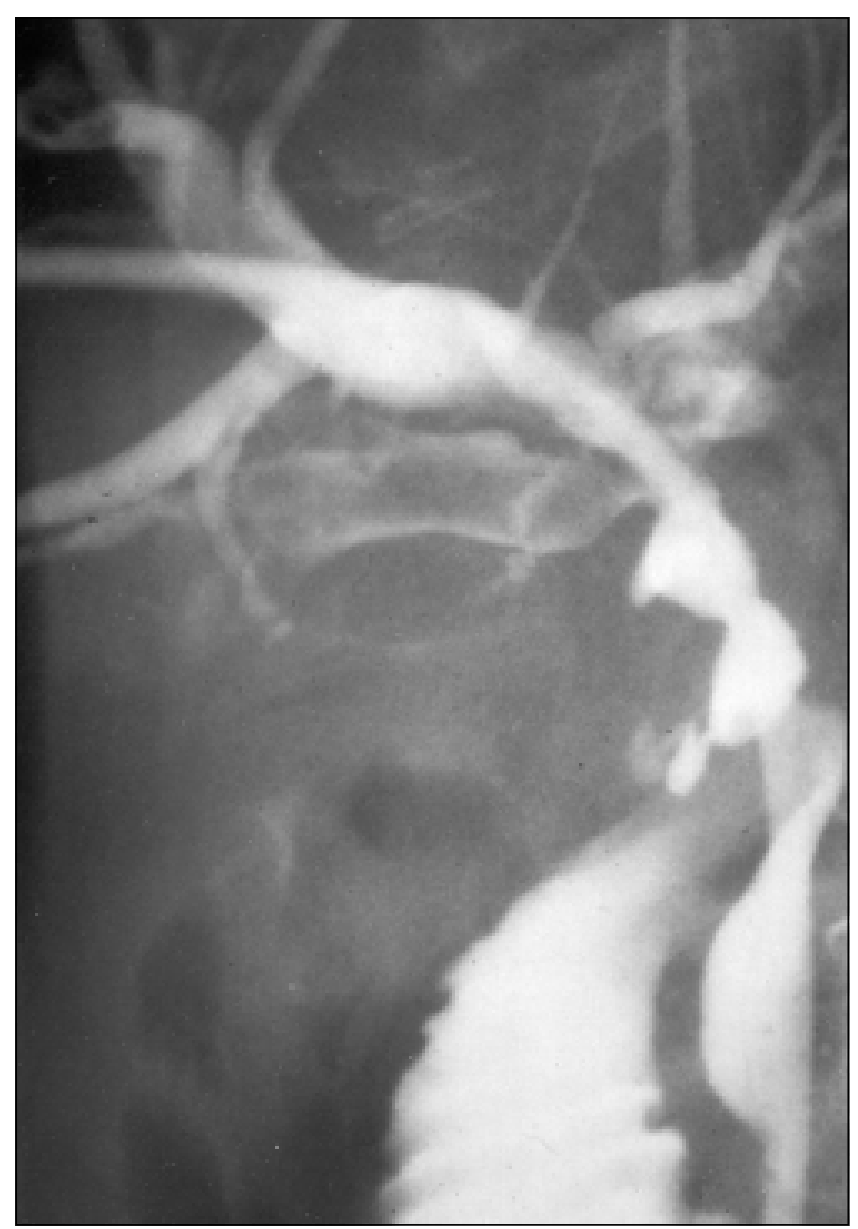

Figure 1) Stricture of the biliobiliary anatomosis after liver transplantation, multiple intrahepatic stones in the left common bile duct and several segments of the right liver lobe, and placement of a 10 French gauge percutaneous transhepatic drainage catheter through the stricture into the duodenum

sis of bilirubin subsequently results in the formation of calcium bilirubinate stones; they are usually characterized as brown pigment stones (2).

Intrahepatic stones frequently induce bouts of cholangitis with a significant risk of sepsis or chronic progression to secondary biliary cirrhosis, portal hypertension and hepatic failure. In the majority of patients, emergency surgery can be avoided by means of antibiotic treatment and percutaneous transhepatic drainage (1). Although endoscopic drainage is superior to surgery for acute cholangitis caused by choledocholithiasis, the procedure is technically difficult and not established for intrahepatic stones $(3,4)$.

The main objectives of definitive therapy are elimination of bile stasis and removal of stones as completely as possible. Residual or recurrent stones should be able to enter the intestinal tract spontaneously. Before treatment, ultrasonography, computed tomography and magnetic resonance cholangiography should be performed to exclude partial liver atrophy and liver abscesses, and localize obstructed segmental ducts that cannot be visualized by endoscopic retrograde cholangiography or percutaneous transhepatic cholangiography (PTC). These procedures are needed to determine

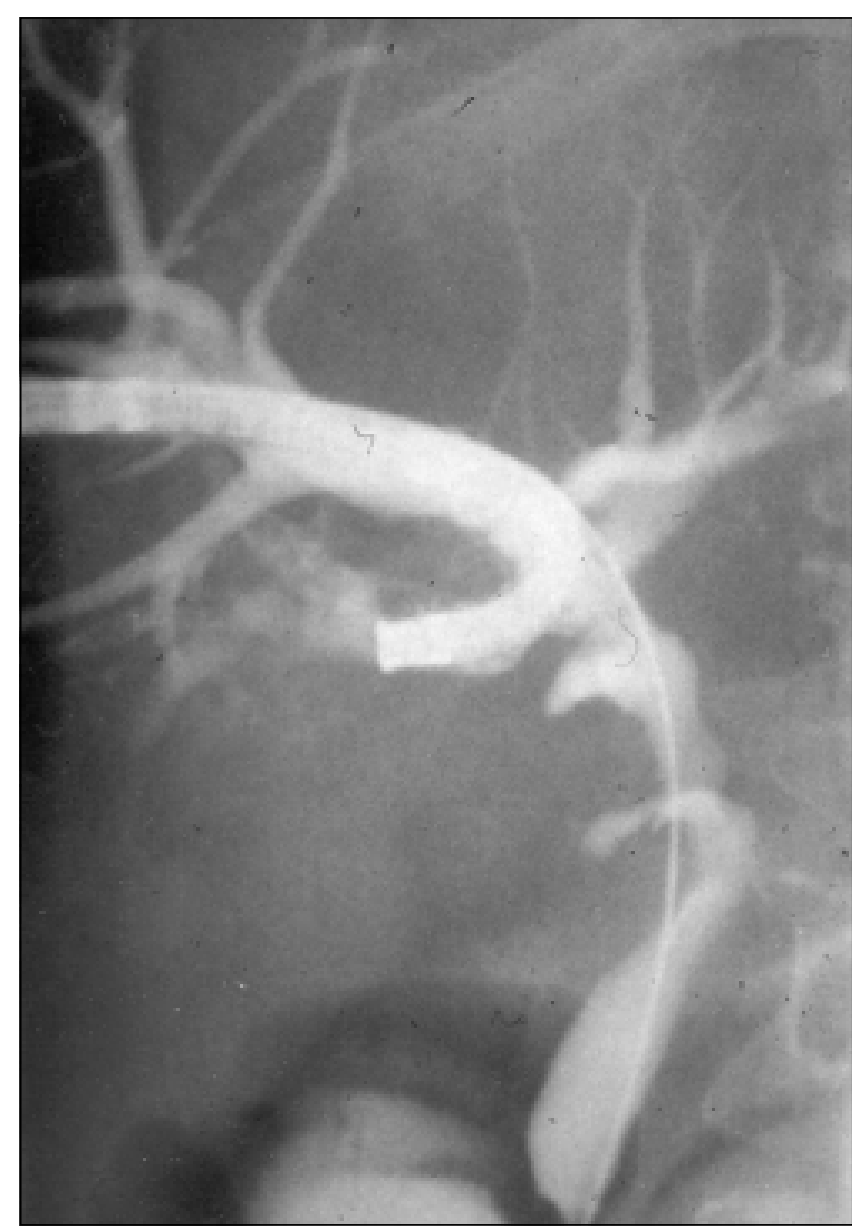

Figure 2) Insertion of a cholangioscope for laser lithotripsy via the right liver lobe into segment 6 after successful disintegration and clearance of the stones in the left hepatic duct

precisely the biliary anatomy and the site of intrahepatic stones and associated strictures. Detection of a tissue mass associated with intrahepatic ducts can indicate cholangiocarcinoma, which has an incidence of $2 \%$ to $10 \%$ in patients with hepatolithiasis $(1,5,6)$. Open surgery or PTC is required for definitive diagnosis.

In patients in whom hepatolithiasis is restricted to the left liver lobe, hepatic resection and left lateral segmentectomy are the best therapeutic options because the source of recurrent infection is completely removed. In contrast, when stones are located in the right liver lobe, hepatic lobectomy is rarely performed due to a high complication rate $(1,7,8)$. In many cases various interventional procedures seem to be at least as effective and safe as surgery, although no controlled trial has been reported so far. The selection of the different therapeutic options mainly depends on the individual anatomy, additional risk factors and local expertise. Many patients, in particular those with recurrences, have to undergo several different interventions, eg, a combination of surgery and percutaneous transhepatic intubation $(1,8)$.

Percutaneous transhepatic drainage and cholangioscopy (PTCS), initially described by Nimura et al (9), has been re- 
ported as the most successful nonsurgical procedure for intrahepatic stones (10). These methods allow a direct approach to all liver segments for drainage, stone disintegration and removal, as well as dilation of associated ductal strictures with subsequent long term intubation.

\section{TECHNIQUE}

Cholangioscopes: Conventional cholangioscopes for intraoperative investigations or bronchoscopes with an outer diameter of up to $4.9 \mathrm{~mm}$ can be used. Smaller steerable cholangioscopes that allow therapeutic interventions have an outer diameter of 3.1 to $3.7 \mathrm{~mm}$ and a channel size of 1.0 to $1.2 \mathrm{~mm}$. These instruments are more flexible than conventional choledochoscopes and are particularly useful for intrahepatic calculi. However, for therapeutic interventions, the small instrumentation channels accept only thin accessories such as minibaskets or laser fibres $(11,12)$.

Lithotriptor systems - Electrohydraulic lithotripsy: Electrohydraulic lithotripsy (EHL) comprises a shockwave generator and probes with a minimal diameter of $0.8 \mathrm{~mm}$ for transmission of the energy to the surface of the stone. A spark discharge from a bipolar coaxial electrode at the tip of the probe induces shockwaves in a fluid medium. Absorption of the energy within the stone leads to a buildup of pressure gradients that subsequently cause stone fragmentation. The frequency and the intensity of the shockwave generation can be adjusted depending on the size and composition of the stones. Although EHL probes with built-in balloon catheters for positioning in the central axis of the bile duct are available, cholangioscopic control of shockwave application is strongly recommended because damage of the ductal wall may occur when the ductal wall comes in direct contact with the probe (13-21).

Laser lithotripsy: Several systems for biliary laser lithotripsy have recently been reported in animal and clinical studies. A flash-lamp, pulsed dye laser with a wavelength of $504 \mathrm{~nm}$ (Candela Company, Wayland, Massachusettes) has been used most frequently (21-27). The laser energy is transmitted via a $200 \mu \mathrm{m}$ or $320 \mu \mathrm{m}$ flexible quartz fibre. Pulses with a duration of approximately $1 \mu$ s can be applied at a repetition rate of 1 to $10 \mathrm{~Hz}$ with an energy output up to $150 \mathrm{~mJ}$. A fluid medium is required for initiation of a laser plasma leading to stone fragmentation. Although conventional laser lithotripsy is probably safer than EHL, direct visual control is recommended because bile duct perforation may occur when the energy is inadvertently applied to the ductal wall $(21,27)$. Intracorporeal cholangioscopic lithotripsy may be further improved by use of a new 'smart' laser with an automatic stone recognition system. This technique allows lithotripsy even under a limited direct visual control or under fluoroscopy (28-31). This flashlamp-excited rhodamine-6G laser has a wavelength of $594 \mathrm{~nm}$ (Baasel Lasertech, Starnberg, Germany). The system provides an automatic cutout on tissue contact. The laser energy is transmitted via a $200 \mu \mathrm{m}$ flexible quartz fibre. The laser light that is backscattered by a surface in the first hundreds of nanoseconds of the pulse is conducted back through the fibre, decoupled by a

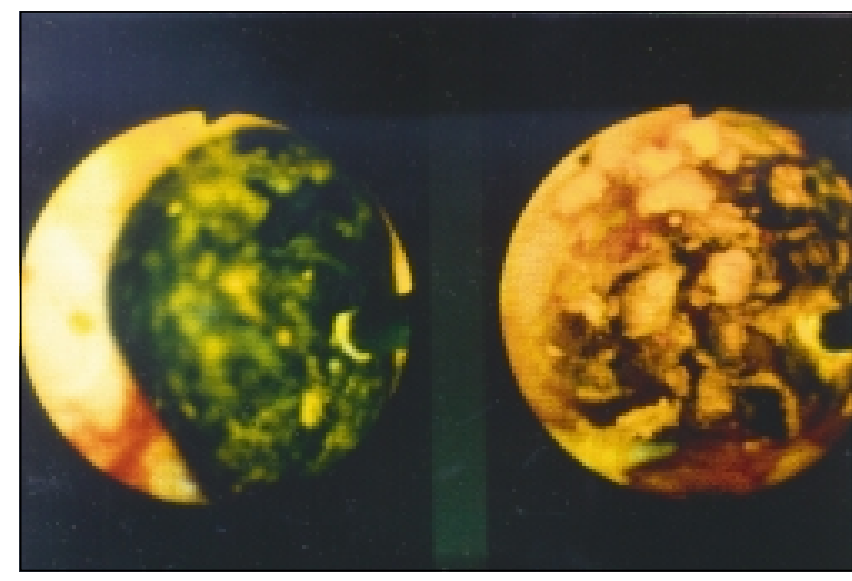

Figure 3) Left Placement of a fibre for laser lithotripsy on the surface of an intrahepatic pigment stone under direct visual control. Right Complete disintegration of the stone in particles with a diameter of 1 to $3 \mathrm{~mm}$ by laser lithotripsy

beam splitter and analyzed. Previous studies demonstrated that tissue and ureter stones can be differentiated using this method. If, therefore, the intensity of the reflected laser beam is below a threshold value that indicates that the fibre is not in contact with a concrement, the pulse is immediately interrupted with the aid of a polarizer by rotating the plane of polarization by $90^{\circ}$. Up to this moment, less than $10 \%$ of the total power of the laser pulse has been emitted, and tissue damage is thus safely excluded. Several uncontrolled series demonstrated the efficacy and safety of 'smart' lithotripsy under fluoroscopy or cholangioscopy with miniscopes $(28,29,31)$. The first randomized, controlled trial of intracorporeal laser lithotripsy (ILL) versus extracorporeal shock-wave lithotripsy (ESWL) was performed in $60 \mathrm{pa}$ tients with bile duct stones in whom standard extraction including mechanical lithotripsy failed or in whom the papilla was not accessible, thus requiring percutaneous access (30). Bile duct clearance was achieved in 22 of 30 patients (73\%) in the ESWL group and in 29 of 30 patients $(97 \%)$ in the ILL group $(\mathrm{P}<0.05)$. The number of treatment sessions and the duration of treatment were also significantly shorter in favour of ILL. Two minor complications occurred in each group; there was no 30-day mortality. This study shows that ILL is more effective in the treatment of difficult bile duct stones than ESWL in terms of stone clearance rate and treatment duration. The smart laser can be used under fluoroscopic targeting without the need for cholangioscopic control $(28,30)$. This approach is less technically demanding and probably more cost effective. However, targeting of stones can be more difficult because the position of the radiolucent fibre inserted through a catheter is not visible. In addition, steering of the catheters is limited compared with that of bidirectionally manoeuvrable miniscopes.

\section{PATIENT PREPARATION}

A medical history, and physical and laboratory investigation are required before percutaneous transhepatic cholangiographical drainage. Attention should be paid to the coagula- 
tion status. Transabdominal ultrasound should be performed for determination of intrahepatic bile duct dilation and measurement of common bile duct size. Aims, risks and alternatives of therapeutic PTCD must be explained to the patient, preferably one day before the procedure. The patient should ingest no solids and liquids for at least $6 \mathrm{~h}$ before percutaneous interventions to minimize the risk of aspiration. An intravenous line is mandatory because repeated doses of sedation and analgesics may be needed. Monitoring of vital signs and level of consciousness is required throughout and immediately after the examination. For patients with heart disease and/or pulmonary problems, oxygen administration may be helpful, and pulse oxymetry as well as blood pressure monitoring must be considered. Perioperative administration of antibiotics (mezlocillin, amoxicillin with clavulanic acid, cefotaxime or cefuroxim) is strongly recommended, particularly when adequate biliary drainage cannot be achieved after PTC and therapeutic interventions. It is essential to autoclave cholangioscopes to reduce the risk of cholangitis.

\section{PROCEDURE}

Percutaneous access to bile duct stones: A transhepatic fistula (sinus tract) must be established for percutaneous treatment of bile duct stones in patients with no $\mathrm{T}$ tube or with a difficult $\mathrm{T}$ tube tract causing intra-abdominal loops that make insertion of catheters or cholangioscopes impossible. Following PTC, an 8 to 10 French gauge drainage catheter is inserted over a guidewire into the biliary tree through the right lateral chest wall or the epigastric abdominal wall depending on the individual anatomy and the location of the stones. The catheter should be passed through associated biliary strictures or a stenotic papilla or biliodigestive anastomosis if present, to facilitate subsequent stone clearance and to prevent rapid stricture recurrence. The cutaneobiliary fistula is dilated every second day in one to three sessions by replacing PTC catheters of progressively increasing diameters $(9,23,29)$. These procedures can be performed under conscious sedation and analgesia. This gradual sinus tract technique is safer than dilation as a single step procedure (14). Cholangioscopy can be carried out as early as seven to eight days after the initial PTC procedure through the stabilized fibrous cutaneobiliary fistula $(14,23,29)$.

Percutaneous stone removal: Stones should be extracted percutaneously only through sheaths unless the sinus tract was created three to four weeks before the procedure. Otherwise, disrupture of the fistula may occur. A safe, rapid and effective alternative is the prograde removal of concrements through the papilla or through a pre-existent biliodigestive anastomosis, preferrably after intracorporeal lithotripsy $(14,23,29)$. For this purpose, a cholangioscope can be inserted into the biliary system through the mature cutaneotranshepatic fistula or the $\mathrm{T}$ tube tract under direct visual control without the need for guidewires or sheaths or overtubes. Effective irrigation can be achieved by saline infusion connected to the instrumentation channel. Cholangioscopy facilitates mechanical removal of smaller stones by pushing them through the papilla or by extracting the fragments with baskets that are inserted through the instrumentation channel and guided under direct vision. Larger or impacted stones can be easily disintegrated with EHL or laser treatment comparable with peroral cholangioscopy. The advantage of the more expensive laser technique is that the fibres for transmission of the energy can be inserted through miniscopes, and the resulting stone fragments are smaller than fragments after EHL and, therefore, can be more easily removed through a stricture, the papilla or a biliodigestive anastomosis $(23-25)$. The procedure is probably even safer when systems with an automatic stone recognition system are used because cholangioscopic vision can be limited due to stone fragments or biliary sludge (28-31). In general, the image quality is much better than during peroral cholangioscopy because the instruments have more fibres than a babyscope or are equipped with a charge-coupled device chip and fragments can be better flushed away from the tip of the endoscope. Therefore, complete bile duct clearance can usually be achieved within a single treatment session. Thereafter, the cutaneobiliary fistula closes spontaneously within two to three days. In patients with tight bile duct strictures, prostheses that are occluded at skin level can be left in situ for several months to prevent early biliary restenosis $(10,23,29)$.

\section{COMPLICATIONS AND MANAGEMENT}

The main risks of the percutaneous transhepatic treatment of bile duct stones are related to the placement of the transhepatic catheter and the dilation of the sinus tract or the T tube tract (19). PTC and insertion of an 8 to 10 French gauge catheter may cause hemobilia predominantly due to biliovenous fistulas that close spontaneously when a transhepatic catheter of an appropriate size to compress the bleeding area is inserted far enough that no side holes are located within the sinus tract. A subcapsular liver hematoma usually disappears spontaneously within a few days; forceful dilation procedures should be avoided during this time.

The incidence of cholangitis is increased in patients with incomplete biliary drainage, particularly when multiple stones or bile duct strictures cause obstruction of several liver segments. Prophylactic antibiotics are strongly recommended for these cases. If a sinus tract or a $\mathrm{T}$ tube tract has not been stabilized, migration of the catheter may cause bile leakage and biliary peritonitis. The risk of this serious complication seems to be lower when the tip of a transhepatic catheter is inserted through the papilla into the duodenum or when the catheter is placed via an epigastric approach. Immediate replacement of the drainage catheter or a repeated PTCD drainage procedure is required, which can be difficult because the bile ducts are usually narrow after decompression or due to continuous leakage. Creation of a large-bore transhepatic tract within a single treatment session is associated with a considerable risk of hemobilia due to arteriobiliary fistula formation and bile duct perforation. Although these complications can usually be managed by arterial embolization and bile duct drainage, respectively, gradual dilation is preferred $(14,19)$. 
Pancreatitis is another complication of PTC drainage and is sometimes observed when a large-bore catheter is positioned through the papilla without previous endoscopic papillotomy. Rapid improvement can usually be achieved by placing the tip of the catheter above the papilla with subsequent gradual dilation. After maturation of a cutaneobiliary fistula, cholangioscopic procedures rarely cause serious complications. Minor hemobilia was seen in up to $20 \%$ of patients treated with EHL but could be managed conservatively $(14,15,19)$.

\section{RESULTS}

According to several Eastern and Western trials, percutaneous cholangioscopic electrohydraulic lithotripsy and laser lithotripsy seem to be comparably effective, with success rates of $81 \%$ to $100 \%(5,13-25,28-31)$. The largest series were reported from Asian countries because of the high incidence of hepatolithiasis. The difficult treatment is a challenge for endoscopists, surgeons and radiologists. Yeh et al (32) recently reported 615 patients with hepatolithiasis, of whom 450 initially underwent surgery with or without postoperative cholangioscopy in Taiwan. PTCS was the primary therapy for 165 patients because of a poor surgical risk, previous biliary surgery or refusal of surgery. Cholangioscopy was performed two weeks after initial percutaneous transhepatic drainage and subsequent dilation of the tract. EHL was used for larger stones. No general anesthesia was required. A mean of 5.1 sessions of PTCS was needed for bile duct clearance, which was completely achieved in $81 \%$ of patients. Every fifth patient had at least one episode of cholangitis, and the mortality rate was $1.2 \%$. In patients with difficult ductal strictures, large-bore transhepatic drainage catheters were left in situ for several months to avoid rapid restenoses. Follow-up after PTCS indicates a stone recurrence rate of $33 \%$ after a mean period of 58 months. All but one patient with recurrent stones were nonsurgically managed by PTCS or conservative treatment.

In a further study from Taiwan, Jan and Chen (5) reported the use of PTCS and EHL or laser lithotripsy in $48 \mathrm{pa}$ tients with intrahepatic stones, of whom 40 had previously undergone biliary tract surgery. A large-bore transhepatic fistula had been sequentially established often on an outpatient basis. Complete bile duct clearance was achieved in $83 \%$ of patients, with a mean number of five PTCS sessions. Complications were seen in $15 \%$ of patients, and the short term mortality rate was $2.1 \%$. During a four- to 10 -year follow-up, 16 of the 40 patients with initially successful

\section{REFERENCES}

1. Pitt HA, Venbrux AC, Coleman RN, et al. Intrahepatic stones. The transhepatic team approach. Ann Surg 1994;219:527-37.

2. Maki T. Pathogenesis of calcium bilirubinate gallstone: role of E. coli, $\beta$ glucoronidase and coagulation by inorganic ions, polyelectrolytes and agitation. Ann Surg 1966;164:90-100.

3. Lai ECS, Mok FPT, Tan ESY, et al. Endoscopic biliary drainage for severe acute cholangitis. N Engl J Med 1992;326:1582-6.

4. Khuroo MS, Dar MY, Yattoo GN, et al. Serial cholangiographic appearances in recurrent pyogenic cholangitis. Gastrointest Endosc 1993;39:674-9.
PTCS developed symptomatic or asymptomatic recurrent stones. Only one of these patients underwent surgery. The recurrence rate was statistically higher in patients with associated bile duct strictures.

In the past two years, we performed percutaneous transhepatic interventions in 22 patients with postoperative bile duct strictures and/or ductal stones. ERCP failed because of a difficult anatomy after gastroduodenal or biliary surgery, eg, hepaticojejunostomy. Internal biliary drainage was achieved in all cases. Removal of intrahepatic stones succeeded in all of eight cases by PTCS and laser lithotripsy. The 30-day morbidity rate of $23 \%$ was mainly caused by temporary cholangitis. After a mean follow-up period of $403 \pm 226$ days, all patients were free of symptoms. Metal stents were implanted in four cases, and transhepatic tubes are still in situ in another four patients and were removed in 13 . One patient underwent elective surgery for a recurrent stricture of a jejunal anastomosis. There was no mortality in this series (33).

\section{CONCLUSIONS}

Percutaneous transhepatic interventions are safe and effective for the removal of intrahepatic stones, even in patients who are high risk candidates for surgery or had previous biliary tract operations. A high incidence of procedure-related cholangitis suggests that routine antibiotic prophylaxis is useful. Comparative trials between primary surgery or percutaneous techniques would be of interest in patients with hepatolithiasis not appropriate for partial hepatic resection, which seems to be the best form of treatment. Further improvement of the short term results of PTCS may be possible by use of miniscopes, which are more flexible for introduction through a thinner transhepatic tract in secondary or angulated biliary radicals. Laser lithotripsy, in particular with an automatic stone detection system, is highly effective for stone disintegration and faster than ESWL.

Asian studies demonstrate excellent long term results in patients with hepatolithiasis and without associated bile duct strictures so that surgery can be avoided in this group of patients. On the other hand, in patients with strictures, the rate of recurrent stones or symptoms seems to be higher than that in recent surgical series. Further studies should evaluate whether placement of temporary large-bore transhepatic catheters or stents can overcome these problems (34).

In spite of these promising results, treatment of intrahepatic stones remains a challenging task, and the optimal therapeutic strategy should always be planned by experienced surgeons, gastroenterologists and radiologists.

5. Jan YY, Chen MF. Percutaneous trans-hepatic cholangioscopic lithotomy for hepatolithiasis: long-term results. Gastrointest Endosc 1995;42:19-24.

6. Sheen-Chen SM, Chou FF, Eng HL. Intrahepatic cholangiocarcinoma in hepatolithiasis: a frequently overlooked disease. J Surg Oncol 1991;47:131-5.

7. Fan ST, Lai ECS, Wong J. Hepatic resection for hepatolithiasis. Arch Surg 1993;128:1070-104.

8. Fan ST, Choi T, Lo C, Mok FP, Lai EC, Wong J. Treatment of hepatolithiasis: improvement of result by a systematic approach. Surgery 1991;109:474-80. 
9. Nimura Y, Hayakawa N, Toyada S. Percutaneous transhepatic cholangioscopy. Stomach Intestine 1981;16:681-9.

10. Yamakawa T. Percutaneous cholangioscopy for management of retained biliary tract stones and intrahepatic stones. Endoscopy 1989;21:333-7.

11. Neuhaus H, Hoffmann W, Classen M. Laser lithotripsy of pancreatic and biliary stones via 3.4 and $3.7 \mathrm{~mm}$ miniscopes: First clinical results. Endoscopy 1992;24:208-14.

12. Neuhaus H. Cholangioscopy. Endoscopy 1994;26:120-5.

13. Choi BI, Han JKH, Park YH, Yoon YB, Han MC, Kim CW. Retained intraheptic stones: treatment with piezoelectric lithotripsy combined with stone extraction. Radiology 1991;178:105-8.

14. Bonnel DH, Liguory CE, Cornud FE, Lefebvre JFP. Common bile duct and intrahepatic stones: results of transhepatic electrohydraulic lithotripsy in 50 patients. Radiology 1991;180:345-8.

15. Chen MF, Jan YY. Percutaneous transhepatic cholangioscopic lithotripsy. Br J Surg 1990;77:530-2.

16. Mo LR, Hwang MH, Yueh SK, Yang JC, Lin C. Percutaneous transhepatic choledochoscopic electrohydraulic lithotripsy (PTCS-EHL) of common bile duct stones. Gastrointest Endosc $1988 ; 34: 122-5$.

17. Yoshimoto H, Ikeda S, Tanaka M, Matsumoto S, Kuroda Y. Choledochoscopic electrohydraulic lithotripsy and lithotomy for stones in the common bile duct, intrahepatic ducts, and gallbladder. Ann Surg 1989;210:576-82.

18. Picus D, Weyman PJ, Marx MV. Role of percutaneous intracorporeal electrohydraulic lithotripsy in the treatment of biliary tract calculi. Radiology 1989;170:989-93.

19. Jeng KS, Chiang HS, Shih SC. Limitations of percutaneous transhepatic cholangioscopy in the removal of complicated biliary calculi. World J Surg 1989;13:603-10.

20. Hwang MH, Tsai CC, Mo LR, et al. Percutaneous choledochoscopic biliary tract stone removal: experience in 645 consecutive patients. Eur J Radiol 1993;17:184-90.

21. Bhatta KM, Rosen DI, Flotte TJ, Dretler SP, Nishioka NS. Effects of shielded or unshielded laser and electrohydraulic lithotripsy on rabbit bladder. J Urol 1990;143:857-60.

22. Ponchon T, Gagnon P, Valette PJ, Henry L, Chavaillon A, Thieulin F. Pulsed dye laser lithotripsy of bile duct stones. Gastroenterology 1991;100:1730-6.
23. Neuhaus H, Hoffmann W, Zillinger C, Classen M. Laser lithotripsy of difficult bile duct stones under direct visual control. Gut 1993;34:415-21.

24. Cotton PB, Kozarek RA, Schapiro RH, et al. Endoscopic laser lithotripsy of large bile duct stones. Gastroenterology 1990;99:1128-33.

25. Ponchon T, Gagnon P, Valette PJ, Henry L, Chavaillon A, Thieulin F. Pulsed dye laser lithotripsy of bile duct stones. Gastroenterology 1991;100:1730-6.

26. Nishioka NS, Levins PC, Murray SC, Parrish JA, Anderson RR. Fragmentation of biliary calculi with tunable dye lasers. Gastroenterology 1987;93:250-5.

27. Murray A, Basu R, Fairclough PD, Wood RFM. Gallstone lithotripsy with the pulsed dye laser: in vitro studies. Br J Surg 1989;76:457-60.

28. Ell C, Hochberger J, May A, et al. Laser lithotripsy of difficult bile duct stones by means of a rhodamine-6G laser and an integrated automatic stone-tissue detection system. Gastrointest Endosc 1993;39:755-62.

29. Neuhaus H, Hoffmann W, Gottlieb K, Classen M. Endoscopic lithotripsy of bile duct stones using a new laser with automatic stone recognition. Gastrointest Endosc 1994;40:708-15.

30. Neuhaus $\mathrm{H}$, Zillinger C, Born P, et al. Randomized study of intracorporeal laser lithotripsy versus extracorporeal shock-wave lithotripsy for difficult bile duct stones. Gastrointest Endosc 1998;47:327-44.

31. Schreiber F, Gurakuqi GC, Trauner M. Endoscopic intracorporeal laser lithotripsy of difficult common bile duct stones with a stone-recognition pulsed dye laser system. Gastrointest Endosc 1995;42:416-9.

32. Yeh YH, Huang MH, Yang JC, Mo LR, Lin J, Yueh SK. Percutaneous transhepatic cholangioscopy and lithotripsy in the treatment of intrahepatic stones: a study with 5 year follow up. Gastrointest Endosc 1995;42:13-8.

33. Schumacher B, Jansen M, Fritzsche K, Preiss C, Neuhaus H. Perkutane transhepatische Therapie endoskopisch unzugänglicher postoperativer biliärer Stenosen oder Gangsteine. Z Gastroenterol. (In press)

34. Neuhaus H, Zillinger C, Illek B, Hoffmann W, Classen M. Percutaneous transhepatic cholangioscopy (PTCS) for laser lithotripsy of bile duct stones: medium-term follow-up in 55 patients. Gastroenterology 1994;106:A352. (Abst) 


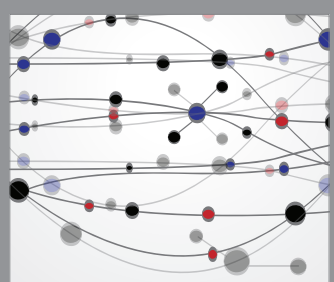

The Scientific World Journal
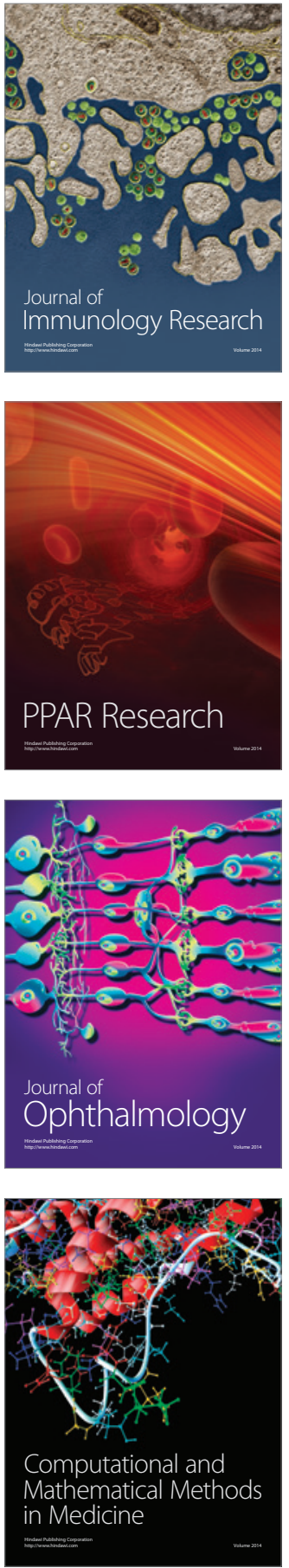

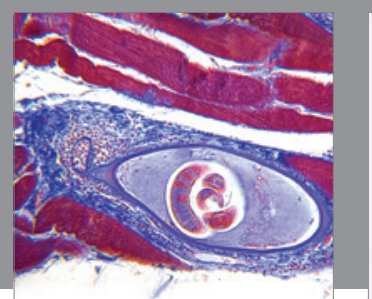

Gastroenterology Research and Practice

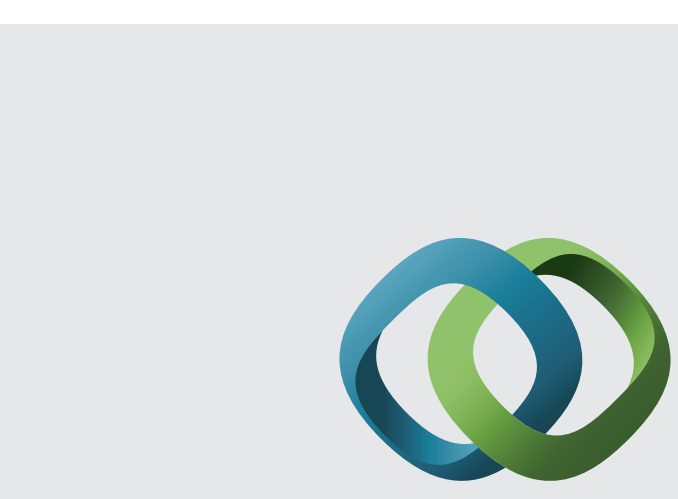

\section{Hindawi}

Submit your manuscripts at

http://www.hindawi.com
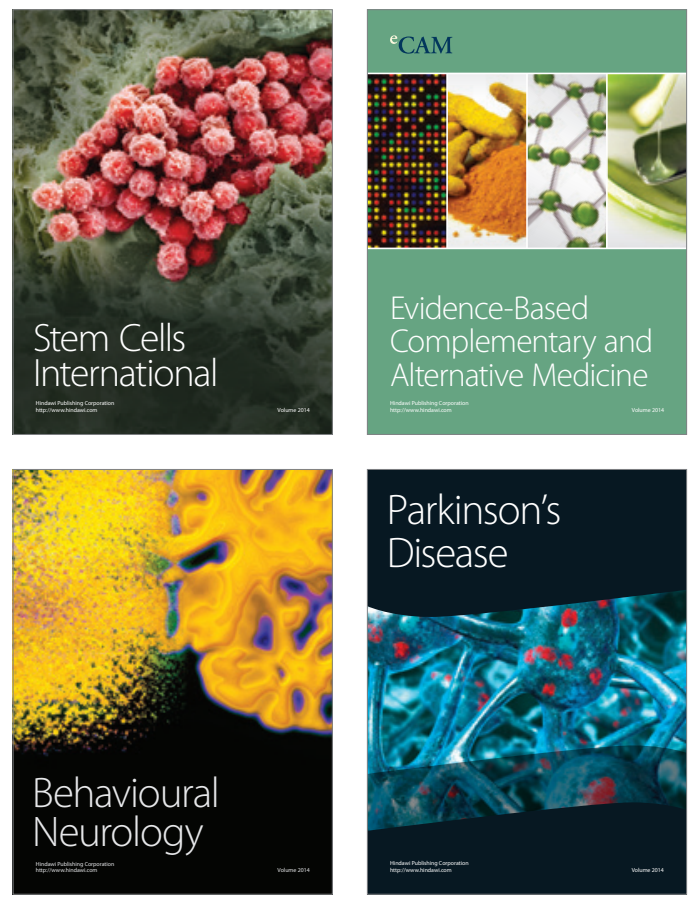
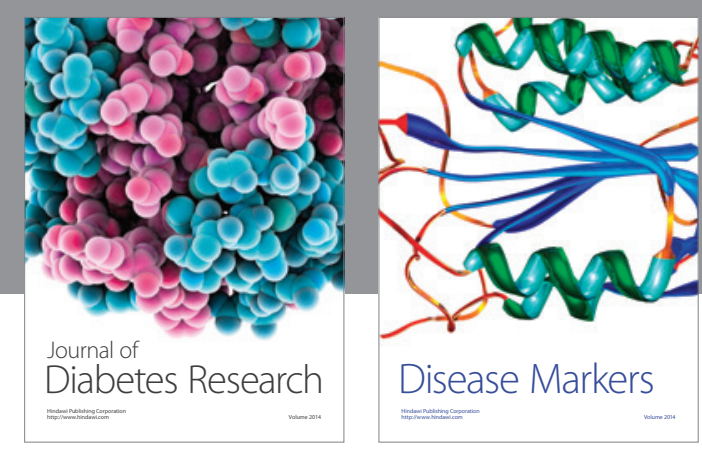

Disease Markers
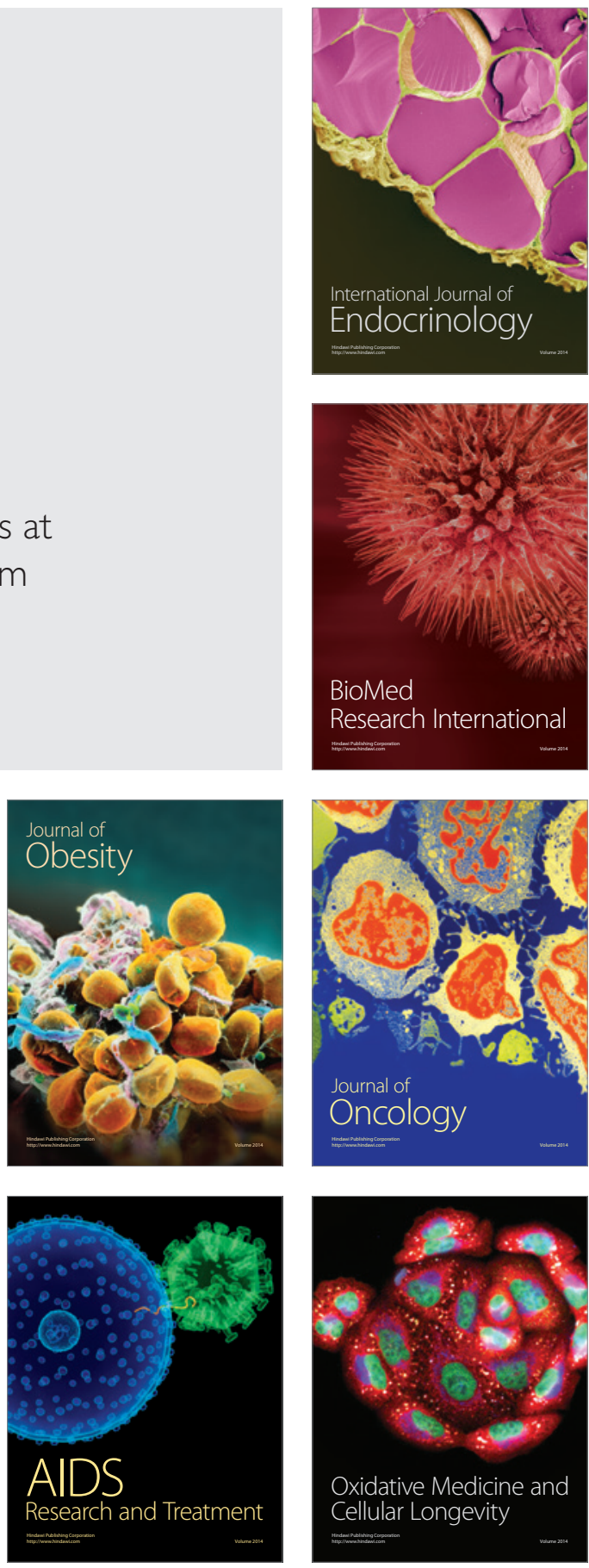